\title{
Hippocrates' Dream. What has Hippocratic Revolution Left in Modern Medicine
}

\author{
Giuseppe Gullace ${ }^{1 *}$, Gabriele Catena ${ }^{2}$, Quintilio Caretta $^{3}$ and Slobodan Dodic ${ }^{4}$ \\ ${ }^{1}$ Consultant Cardiologist, Multimedica Hospital Group, Adjunct Professor, University of Florence, Italy \\ ${ }^{2}$ Director of Cardiologia Territoriale, Teramo, Italy \\ ${ }^{3}$ Associate Professor, Department of Experimental and Clinical Medicine, University of Florence, Italy \\ ${ }^{4}$ Professor at Medical Faculty, University of Novi Sad, Institute of CVD Vojvodina, Serbia
}

Submission: January 30, 2019; Published: March 01, 2019

*Corresponding author: Giuseppe Gullace, Consultant Cardiologist, Multimedica Hospital Group, Cardiology, University of Florence, Italy

\begin{abstract}
Hippocratic revolution in Medicine has been an extraordinary event considering the years when it occurred and the medical situation of that time. The struggle against philosophers and priests was tough and winning their beliefs was even more difficult and complicated. Anyway, the greatness was that of having laid the underpinnings of Medicine whose principles are still alive today and constitute the foundations of the Modern Medicine. Nevertheless, many of these principles are disregarded in clinical practice today and sometimes constitute real critical issues within the health system. This review reports some information about the ancient long period of practicing medicine until Hippocrates' period, taking into account the main structure of Hippocratic revolution and comparing, with the eyes of one who is daily an observer operating on the battlefield, those principles that today occur in the Modern Medicine practice. Critical issues are discussed, and some proposals are suggested, just as personal opinions, coming from experience and daily activity in continuous contact with patient.
\end{abstract}

Keywords: Hippocrates' dream; Modern medicine; Hippocratic Oath; Rock inscriptions; Hunting; Fighting; Priestly medicine; Internal pathology and bone surgery; Etiology; Health Organization; Physician-Patient relationship; Communication; Humanization

\section{Introduction}

The practice of Medicine since its origins has evolved going to meet many changes; to go back to history and to follow this evolution you have the feeling of being "tourists in search of a certain mysterious charm of the past that helps us to achieve the future" [1]. But also fascinated in looking for all those elements that help us to understand the changes and to guide us in correcting the errors of the present. "Describing the past, understanding the present, predicting the future: this is the task of medicine"[2]. There are still many Hippocratic principles that remain cornerstones of Modern Medicine, written in the Hippocratic Oath, either in its ancient [3] or in its modern version [4], on which the new graduates in Medicine and Surgery swear at the time of graduation. Today, Medicine is at a very high level of evolution (knowledge of diseases, technological development, knowledge of new therapeutic interventions, etc.) with an awesome improvement in diagnostic and therapeutical procedures as well as in the field of training, planning, management and implementation; nevertheless, it remains quite complex and for this, with difficult interpretations, inappropriateness's, possible human errors that sometimes are unpredictable.

In this article we imagined, arbitrarily and presumptuously, to be in the shoes of Hippocrates and to try to see what Medicine was in his time, how much it has left today of that extraordinary revolution and how much could remain for its immediate future.

\section{Medicine before Hippocrates}

It is important to try to understand how civilization developed and with it Medicine itself from its origins going back to history looking for information and evidences that are often scarce and fragmented. Archaeological findings, rupestrian graphic signs and later writing are the main information we get from the past. Communication, the need of primitive man to transmit information and habits, arose before learning to speak and did it so through rock inscriptions. The information available dates from the 50,000 years B.C., a period of great migrations, a period in which the migration of Homo Sapiens from Africa to Europe and his meeting with Homo Neanderthaliensis is supposed to have happened. But contrary to what usually happens in the history, it has not been the male Sapiens looking for the Neanderthal woman but the Sapiens woman looking for the Neanderthal man. Recent studies of genetics show that the genome of modern Europeans is constituted by $1 \%-4 \%$ by Neanderthals and as regards to the female quantity it is more represented by woman Sapiens. From this union the descendants inherited from the former a clearer and more resilient skin, a strengthening of the immune defenses, but 
also type 2 diabetes, autoimmune diseases, biliary cirrhosis and Crohn's disease [5-7]. This is probably also linked to the change in eating habits with a progressive increase in meat consumption.

The man of this period, as can be seen from the rock inscriptions dated around 50,000 years B.C. and later, understood the wounds or death resulting from hunting, fighting or accidental events. To treat these, they used simple and instinctive means, based on the observation and imitation of the animals and on direct experience (for example: the wounded animal looking for refreshment in cold water or eating a specific plant to get rid of parasites) and on the caring (for example: the help of older woman given to the woman in labor, the instinct of protection and attention given by the mother to her child). However, he did not understand the evil when it struck men without any apparent reason and outside the aforesaid circumstances. The disease was then regarded as an invisible enemy sent by supernatural forces or by the gods as divine punishment. Medicine was born, therefore, after the encounter of man with the disease, and aimed at healing or soothing physical suffering, with all the available means. The Medicine of this period and for millennia, as considered divine punishment, was practiced by priests (Priestly Medicine) and the disease treated with prayers, magical rites, pleadings, invoices, spells and sacrifices or practiced by sorcerers, magicians or shamans (Magic Medicine) with manual interventions and administration of substances. Subsequently, Empiric Medicine began to appear, based on observation, processing and reproduction of natural phenomena, the first observation between a cause and an effect; treatments were carried out by selecting plants and natural substances capable of healing the disorders and therapeutic practices derived from experience [8-9].

Later, all three forms of Medicine have merged: the religious component served to determine the etiology (the divine wrath, the supernatural attacks the man causing the onset of the disease), the magic component had relevance in the therapeutic interventions and the empirical one was applied to know the disease and its evolution and the way to treat it, the first embryo of scientific Medicine. Although the three forms of medical practice remained for centuries, the empirical one developed more and evolved towards scientific Medicine.

An early form of Medicine as a system has been observed around the third millennium B.C. in Mesopotamia, the area defined as a fertile crescent. It is in this area that the writing was born by the Sumerians who had to satisfy the need to catalog the products. In fact, being their system of government of theocratic socialist type, all the production was stored, cataloged and then redistributed; the cataloging that was initially made with simple signs as the products increased became complex; hence, the birth of the cuneiform signs and subsequently the cuneiform writing. In the epic poem "Enmerkar and the lord of Aratta" it is told that king Enmerkar sent several times a messenger to say (verbally reported message) to the king of Aratta to submit to him. Due to the repeated denials of the king, "...the lord of Aratta took a clod of clay and wrote words on it like a table. Never had a word written on clay. But now, since the god of the sun had inspired him so, it happened. And Enmerkar wrote the table ... "in this way he was sure that the message had been exactly referred and that the recipient had understood it perfectly [10].

The Medicine at the Sumerians was characterized by a highly scientific diagnostic approach, and the prescriptions were referred to therapies and surgery; they were the first to use the method of Haruspicina that centuries later was widespread among the Etruscans, that consisted in the search for signs of illness and information comparing the patient's data with those of a sheep's liver; the Ur Nammu code is Sumerian, the first ever law on the professional responsibility of the medical art operator. At the Sumerians, the Caduceus was born, symbol of Enki, the god of the earth, benevolent with men, formed by two serpents coiled around a stick [11-12]

However, the Medicine in Mesopotamia, the Akkadian, Assyrian and Babylonian, remained at an empirical and observational level for many centuries after the Sumeric era. Much of the information comes from clay tablets compiled at the time of Assurbanipal, an Assyrian king who had a large and important library, found in Nineveh, the ancient Assyrian capital. In these, medical procedures and other topics such as hygiene, recipes and surgical operations, were recorded (and used as teaching). In this area the first plant-based pharmacopoeia with about 250 varieties of substances was born, the first suppository based on aromas and the use of alcohol to disinfect; the anesthesia was induced with indian hemp and mandrake root, imported from Persia and India, but the Assyrians introduced a new effective method to "anesthetize": compression of the carotid artery at the level of the neck to cause cerebral ischemia and a semicomatous state that prepared surgery. Regarding the diagnosis, when it was difficult, the patients were exposed in the square with express request to travelers if they had the opportunity to see before and in other places such patients with those symptoms and to report to the authorities especially about how they were treated $[13,14]$.

In Babylonia, doctors were trained in the theory (with the description of the diseases and the treatment to be taken) and in the practice of medical art by a renowned master; they were taught the rituals of exorcism. The doctor (asu) intervened later with the medicines after the magician (ashipu) had failed to get any effect from the magical practices. The code of Hammurabi was edited in this period (subsequent, however, to the Ur Nammu code, but, anyway, more detailed and complete than this). The place of the intellect was in the heart, the essential place of life was in the blood and the central organ of circulation was the liver (predictions and auspices were drawn from the position, the irregularities and the shape of the animals' liver). The diagnosis for the Assyrian-Babylonian people was focused on the observation of the liver, considered the origin of the blood and therefore the most important organ and therefore the object of most prescribed rites $[10-14]$. 
Egyptian Medicine, followed that of Sumer and was some centuries antecedent to the Mesopotamian one, represented the first medical organized and articulated system. At the time of the Fourth Dynasty under the pharaoh Djoser, Imhotep, physician and architect, grand vizier of the pharaoh and head of all the doctors of Egypt, began to put the bases of such health and medical organization that we know today through the famous medical papyri written in a later period, from the end of the ancient kingdom (2100 B.C.) and until the new kingdom (1000 B.C.).The Hearst papyrus (2000 B.C.), reports the treatments of diseases related to the urinary system, blood, hair and teeth, the Rameusseum papyrus (1900 B.C.), composed of 17 papyruses dealing with eyes, gynecology, pediatrics, muscles and tendons and describes recipes and magic formulas; the Kahun papyrus (1850 B.C.) which is a compendium of gynecology, where it is reported a disease that "devours tissues", cancer, but also deals with different issues such as obstetrics, veterinary and arithmetic, the Ebers papyrus (1550 B.C.) comes certainly from the library of a medical school and is one of the most important and largest written documents of ancient Egypt. Medical book model, contains notions of anatomy, a list of diseases and related treatments, remedies for many diseases, from cough to heart problems and 900 recipes of drugs, the first written report on cancer; his 877 paragraphs describe numerous diseases in various fields of medicine such as surgery, general medicine and several specializations including pediatrics, gerontology, ophthalmology, gynecology, gastroenterology, diseases of the anus and their corresponding prescriptions; Edwin Smith papyrus (1650 B.C.) is a treatise on internal pathology and bone surgery, lists 48 cases of wounds and injuries, with the corresponding therapies, has a mainly surgical content; medical information includes the objective examination, diagnosis, treatment and prognosis of numerous diseases, with special interest in various surgical techniques and anatomical descriptions, obtained during the embalming and mummification processes of cadavers; the medical Chester Beatty papyrus, the magic remedies of headaches and proctology; the Carlsberg papyrus deals with eye diseases and pregnancy.

Within the numerous descriptions offered by the Egyptian texts there is the heart and the circulatory system, collected in the treatise: "The secret of the physician: knowledge of the heart", incorporated in the papyrus of Edwin Smith, in which the heart is defined as a mass of meat, origin of life and center of the vascular system; through the pulsation, the heart speaks to the vessels and to the limbs of the body, that is, the heart pumps blood to the whole organism through the vessels. The health organization provided the training of physicians in the "house of life" both in the theoretical and practical parts; they were subsequently authorized for professional practice, accredited by the Grand Vizier and subdivided into general practitioners and mainly medical specialists, physicians and doctors of the people, they had medical insurance and a sickness license, they had a working time of 8 hours per day and the right to a pension. All were part of a National Health System that provided free treatment for the citizens and shelter in the House of Health; non- office care was paid in kind. In addition to physicians, medical inspectors, the chief pharmacist, the nurse and the midwife, were included in the system. In the presence of a patient, the physician proceeded through the symptoms and the detection of the signs to define the disease (diagnosis), to identify the possible cause that determined it (etiology), to define the type of therapeutic intervention (therapy) and for how long (prognosis). The phrase attributed to Imhotep is significant: the disease that I know to care is favorable, doubtful that I fight, unfavorable that I do not know to treat (Papyrus by Edwin Smith). It is worth mentioning that in a civilization where there was no difference between a man and a woman from a social point of view, there were female physicians (as, indeed, pharaoh and judge women) who held high positions like Peseshet, gynecologist, first woman Gran Vizier some century after Imhotep [15-22]. Herodotus wrote that Medicine in Egypt was broken down so that every physician deal with one and only one disease; there was a great number of physicians, those of the eyes, of the head, of the teeth, of the abdomen, of the anus, of the diseases with uncertain localization and then the occupational physicians, the physicians of hygiene and those of the birth. The Egyptian physicians were so good and famous that the Pharaoh sent them on request for consultation with foreign Courts [23].

\section{Greek Medicine and pre-Hippocratic context}

The following centuries did not change Medicine into its fundamental pillars, that were to perceive illness as a divine punishment, for which Medicine maintained its rational and empirical base which gradually evolved. The asclepiads, the first temples/hospitals in which the patient was left in the evening with the hope that the divinity descended and through the prophetic dream the next morning (after incubation) would be found healed and the medical record with the tablets found in the Epidaurus temple where the patient's name, his symptoms and the evolution of the disease were recorded. The rational empirical basis has developed with the increase of observation and analysis of the phenomena. In the middle of 600 B.C. the medical school of Miletus was born: his illustrious masters were Anaxagoras (who first stated that for the birth of a new life it was necessary the contribution of the male and female seed) and Anassimandro (who described how the human embryo, in its early stages, was very similar to that of fish). The masters of Mileto sensed that the brain was the center of control of the psychic and somatic functions and that the sense organs were connected to it through the nerves.

Around the middle of 550 B.C. the school of Crotone was born with Democede, family and itinerant physician (was also called by Darius when his wife Atossa, daughter of Cirus, was discovered to have a tumor of the breast) and Alcmeone, a pupil of Pythagoras, who performed the first autopsies on cadavers, recognized the place of emotions in the brain and attributed to it and not to the heart the functions of control of the senses, of motion and of human activities, defined the concept of health as a balance between the four elements and the opposite properties, recognized the great influence of nutrition and health, was the founder of the scientific 
method, anatomy, physiology, embryology, psychology [2,24-28] and scientific observation and experimentation. He rejected the concept of illness as divine punishment and the magical rites adopted to treat it, stating that the disease depended on purely natural and chemical processes.

\section{The medicine of Hippocrates and the hippocratic rev- olution}

The Medicine of Hippocrates' period was an art founded on empirical knowledge and practiced by physicians, expert men, without professional qualifications recognized by law, who learned general knowledge and technical skills through an apprenticeship with a great teacher. It was still a Medicine with a strong religious component in the cause of the disease and magical in the adoption of interventions to heal it. The Corpus Hippocraticum is the collection of about sixty works, not all attributable to Hippocrates, which contain letters, essays, recipes, aphorisms, researches and notes without a particular order and which represents the Hippocratic Medicine, its fundamental bases, its teachings, referring to a context in which Medicine itself was changing thanks to the theories and studies of Alcmeone and Democede from Crotone [29-32].

Hippocrates had to engage in a tough fight against:

1. The conception of illness as a divine punishment

2. The proponents of superstitious beliefs and of magicalreligious practices in medicine (...man cannot be contaminated by a god: being in fact the former corruptible and the latter sacred, it would be at most purified and sanctified, but certainly not offended) [30].

3. Those who denied the validity of medicine as fruitful mediation between theory and experience [30].

4. Representatives of the philosophical medicine of postulates [30].

The first foundation is in line with the thought of Alcmeone and is represented by the definition of certain circumstances entirely human that correspond to a situation of imbalance of the four humors of the body. Medicine had the function of restoring the balance between humors using the scientific method.

With this fight the great Hippocratic revolution of Medicine started; it was based on the scientific method and consisted of the passage from the practice of magical rites to its conception of science founded on the alliance between physician and patient (...I will define what I believe to be Medicine: as a first approximation, get rid the sick from suffering and containing the violence of the disease and not treating those who are now overwhelmed by evil) [33], very similar to the phrase attributed to Imhotep above reported (papyrus of Edwin Smith); from the patient as an object to be treated to his consideration as a person, from disease as divine punishment to his definition of scientific entity dependent on natural and chemical phenomena due to the imbalance of humors, from suffering considered as a punitive disgrace to his classification as lived with dignity, from the hospitalization experienced as fatalistic expectation to active care full of hope, from the diagnosis made with observation to its consideration as a complex and articulated process, from the therapy practiced with religious rites and magical practices to the use of medicaments, diet and physical activity and, finally, from the prognosis dependent on the benevolent intervention of the gods to the physician's ability to adopt the appropriate therapeutic interventions for the patient's recovery and healing. All these concepts have been well summarized by Aristotle's later definition of the two aspects of Medicine: scientific and clinical that means science and art; science as organized knowledge of all circumstances related to man's health and art as capability to apply knowledges to care man's illness.

The principles on which the Hippocratic revolution was founded are theoretical, productive, practical and formative.

1. Theoretical: linked to the epistemology that is the discipline that studies the fundamentals, the methods, the validity, and the limits of scientific knowledge, keeping Medicine separate from philosophy. Process of anamnesis, diagnosis, prognosis and therapy (Describe the past, understand the present, and predict the future.

This is the task of Medicine - Hippocrates), based on trial and error, through:

- $\quad$ causal explanation (etiology)

- $\quad$ observation of the patient (clinic)

- $\quad$ detection of indications (semeiotics)

- $\quad$ aware process of data processing (diagnosis)

....we must start from the beginning of the disease and from many discourses and acquisitions of knowledge realized little by little, after we must proceed to put together the data and realize if they are similar among them, and then we must observe the dissimilarities, if they are similar to each other, so that a single similarity arises from them: this is the method and so there is the approval of what is good and the disapproval of what is not good... [34]....it is more important to know what kind of person has a disease than what kind of illness a person has- [31]...verum scire est scire per causas (to know the truth is to know its causes) [35].

The Medical Practice is a process starting with the problem presentation, investigated by physician through the anamnestic assessment, subjective symptoms and objective clinical signs detected by physician; then, a general assessment of the situation is needed in order to have a diagnostic orientation (supported by the experience and knowledges) and hypothesis of possible disease that could have any causal explanation of symptoms/ signs onset.

2. Productive: linked to the therapeutic strategy based on diet/drugs/surgery (therapy). The importance given to the lifestyle of the patient (dietetic, atmospheric, psychological, even 
social elements), typical of medical practice, allowed to understand and defeat the disease from which he was suffering....... Let the food be your medicine and your medicine be the food. It is not enough to foresee the disease to heal it, it is necessary to teach health to preserve it. (Hippocrates). I will regulate the standard of living for the good of the sick according to my strength and my judgment; I will refrain from bringing harm and offense. (Hippocratic Oath).

3. Practical: Linked to the physician-patient dialogue, to verbal observation and communication.......if there is love for man, there will also be love for science [31].

.....it seems to me that we should, speaking of this art, say things that are understandable to the profane ... if the understanding of the common man is missed and the interlocutors will be not put in such an arrangement, it is the reality that will miss .... it would not be possible to know medicine for those who do not know what man is; but this is what must understand who has properly treat men [31].

The relationship between physicians and patient was born as a friendship between unequal, an unbalanced and asymmetric relationship between the knowledge and power of the physician and the passive dependence of the patient. The search for a unity of purpose between the physician (responsible for the treatment) and the patient (need to be adequately cared for) aim to lead to dialogue and mutual adaptation of one to the needs of the other with the purpose of regaining or maintaining health, through scientific, professional and human knowledge [35].

4. Education: Linked to the ability to transform medicine from a family art to a discipline that can be taught to others.

- To esteem my master of this art as my father and to live with him and to help him if he needs and that I will consider his children as brothers and I will teach this art, if they wish to learn it, without requiring compensation or written pacts;

- $\quad$ To share my children and the children of my teacher and the students bound by a contract and bound by the physician's oath, but no one else, to participate in the precepts and oral teachings and every other doctrine (Hippocratic Oath).

Finally, the instruments represented by:

a. Health documentation (clinical record): collection, recording and cataloging of data, organized according to a rational scheme and compared and verified with experience.

b. Mechanical instruments: instruments for phlebotomy and orthopedics.... it is necessary that the mechanical instruments are well built or not built at all; it is unseemly, in fact, and a sign of absence of art that those who use mechanical instruments do not obtain the results due. [31].

5. Evolution of Medicine: From antiquity to today, Medicine has undergone a radical evolution in terms of substantial definitions, objectives, modalities and methods. It moved from Magical -Empirical Medicine to Medicine as a System. In fact, from the illness intended as divine punishment, we have passed to the disease defined as a scientific entity framed in a Health System that distinguishes the healthy from the sick, where Health is considered as the culture of being well (Prevention). Regarding the objectives, Medicine moved from the right to assistance and care to arrive today to the protection of the right of health and the guarantee of free assistance and treatment.

Modalities have also evolved from the healing of the disease with the diagnosis and planning of care (Egyptian era) to the improvement of the state of health through personal care (Hippocratic era), to the improvement of the diagnosis through technology development (19th-20th Century) and increase of medical knowledges. Today objectives and modalities of Medicine are to satisfy the customer by providing effective and efficient services. In any case, the original objective remains unchanged, that is to get rid man from the curse of the disease. At the same time the evolution of the method for which Medicine of signs has become anthropological, then technological and finally management medicine has taken place.

6. Modern Medicine: Modern Medicine started slowly in many industrialized countries since the end of last century and the beginning of 2000 with the progressive crisis of Classic Medicine. It has increasingly developed either the scientific or the technological components that produced an increase of knowledges but at the same time also made more evident the dissonance between science and art. The attitude to propose lines of application without precise cognitive assumptions and physiopathological correlations and explanations usually addresses physicians towards technical precision. In Medicine this is useful but not enough; without the critical attitude (Art), Medicine becomes progressively impersonal.

At the end of last century, population has been increased and consequently also the health needs of people, the development of technology and the increased scientific knowledges have given an important contribution to ameliorate diagnosis and surgical and therapeutical interventions such as to reduce mortality. This change needed to give Medicine a new structure with mission, vision and objectives reviewed according with a Public Healthcare model. First, Health is defined as physical, mental and social wellbeing while illness is defined as an alteration of the function of the person's organs but also his history, a chapter in a person's biography, an essential part of the self. Second, Medicine as a System (National Healthcare System) is based on the principles that State protects the right of health and guarantees assistance and treatment and a good healthcare should be available and free to all, regardless of wealth (Art 32 of Constitution of Italian Republic, National Health Service of UK); for this, the organization of health structures and professions is needed and the objectives become treatment of the disease as a scientific entity and of the person with that illness, promotion and maintenance of physical, mental and social wellbeing, protection of the right of health, equality of access to care, uniformity and equity of treatment, optimization of health resources (funding, equipment and facilities) through 
effective management and adequate and efficient organization. It is clear that the core of the health structures is represented by the organization whose operativity is expressed by the management of health based on efficiency, equity, involvement, safety, uniformity, appropriateness and effectiveness with the addition of the research, competence and training of the operators, the technology, the analysis and the control of the processes for the supply of products with quality standards such as to be able to satisfy the needs of those who request them and undergo continuous improvement [36]. In any case Medicine has to guarantee the assistance and care of the patients, has to make any effort to obtain healing when possible (assistance is guaranteed, healing can be obtained but not guaranteed, in any case, everything must be done to get it) and has to protect and guarantee the right to health for every citizen.

The profession of the physician is inserted in this context; more evident the specialistic activity within hospital organization but also important the activity of General Practitioner, whose evolution over the centuries increased his role and professionality. Today's Homo Medicus is an organized and technological figure whose main objective has been sanctioned by the World Medical Association with the declaration of Helsinki in 1964 and still alive: it is the physician's mission safeguarding the health of people. The main competencies of the General Practitioner, not so different from those belonging to Specialist and Hospital physicians, are reported as follows:

1. Primary care approach and management

2. Person-centered care and responsibility of continuity of care

3. Specific acute and chronic problem-solving skills

4. Comprehensive approach including promotion of prevention

\section{Community orientation}

6. Holistic and multidisciplinary modeling applied in medical practice considering the context (environment where physicians work, conditions, culture, community and financial), the attitude (physician's capability, values and ethics), science (critical and research-based approach, educational and quality improvement) [37].

In our opinion, two important aspects are to be evidentiated as critical. First, in the modern health organization the physician (general or specialist) is one of the many figures (nurse, psychologist, specialists, social workers, etc.) that revolve around the patient to whom they give their specialistic contribution of experience and competence but where it is often difficult to understand who is that who has the responsibility for decisionmaking on the patient. Second, development, changing society and the increased people's health needs have changed the problem-solving approach; the increased number of instrumental examinations and specialistic consultations has developed the concept of health marketing (the logic of problem solving has been replaced by the logic of marketing), that contributed, and still continues to contribute, to increase today the number of exams, often inappropriate and unuseful. Other causes of this increase are:

a. Number of physicians (the increase in number leads to demand induction and introduction of financing mechanisms based on production volumes),

b. Social and economic factors (the increase in population income leads to an increase of health demand and consumes, especially if service is free),

c. Environmental factors (overprotective family environment, difficult and inadequate working conditions),

d. Cardiological rehabilitation (only 30\% of the cardiac patients are sent to rehabilitation, this increase rehospitalization and health needs),

e. Cogent factors (bureaucratic practices such as sports, retirement, driving license, etc.),

f. Behavioral risk factors (smoking, sedentary lifestyle, improper nutrition, stress),

g. Lengthening of life (the aging of the population is accompanied by an increase in needs),

h. Technological improvement (the introduction of new technologies in Medicine such as equipments, drugs, care procedures, increases the demand for services),

i. $\quad$ Reduced mortality (increase of the number of disabled and chronically ill; increase of the number of patients with heart failure and re-hospitalization - 30\% at 1 month,> 50\% at 6 months -),

j. Hospital-territory connection (poor and inadequate hospital-territory connection for the integrated polispecialistic management of chronic or heart failure patients or in the rehabilitation maintenance phase,

k. Non-adherence (only $60 \%$ of physicians has adherence to guide lines regarding therapy; the adherence of the patients to therapy is reduced to about $50 \%$ at 6 months),

l. Social security reasons (numerous applications for invalidity or early retirement, increased number of days due to illness)

m. Inappropriateness (inadequate and unnecessary examinations, disconnected from the clinical context, inadequate pathways),

n. Defensive medicine (set of activities that denounces the insecurity and the difficulties of the physicians during his professional practice),

o. Absence of a follow-up plan (difficulty in preparing a package of interventions and control exams to be individualized and scheduled until the objectives are reached), 
p. Health Protection (non-articulated prevention campaigns, not always targeted and adequately controlled; induced and inadequately controlled needs; additional examinations uncoupled from proven clinical-diagnostic utility; health protection intervention activities often disconnected from the general context, social, economic, productive, environmental, etc.).

What has the Hippocratic revolution left in Modern Medicine? In the light of what above reported we try below to deal with some important aspects of Medicine comparing what was the underpinning of the Hippocratic revolution with what frequently happens to day in medical daily practice.

\section{Health/Disease}

Hippocratic definition: health/illness is defined as the natural result of certain entirely human circumstances that correspond to a situation of balance/unbalance of humors.

Modern Medicine: health is defined as physical, mental and social well-being while illness as an alteration of the function of the person's organs but also a history, a chapter in a person's biography, an essential part of the self.

Critical issues: still today many people consider illness as a divine punishment; in the situation of everyday life, disease is highlighted by the presence of a health consumerism with disproportionate demand for care, examinations, drugs and unnecessary, often useless, services that take resources away from indispensable activities.

Comment: An inadequate management of the patient and, in addition, the presence of archaic beliefs that lead us to consider the disease as divine punishment, still contribute to increase the lack of trust in official medicine and to turn to magicians and healers. In the first six months of 2013 in Italy, magicians, sorcerers and healers recorded an increase in their annual turnover of 18.5\%: in fact, it rose to 8.3 billion from 7.5 in the first six months of 2012; there are about 160,000 , which provide around 30,000 daily services. About 13 million of Italians rely on this type of advice spending between 50 and 1000 euros per session, about half of which are addressed for health reasons - Italian Association of Contributors).

\section{Medicine}

Hippocratic definition: Medicine is considered a scientific subject based on reasoning and experience, understood as Science (clinical-scientific knowledge) and Art (ability to apply knowledge to the treatment of diseases). Medicine deals with patient care as a person applying the scientific method, rationality and common sense deriving from experience.

Modern Medicine: treating of the patient as a person using the scientific method and all the necessary instrumental equipment that technological development makes available and applying the Guidelines.
Critical issues: In reality, this evolution of Medicine has led to catalog everything in numbers (it is acceptable if statistically valid), to evidence-based medicine, to the drafting of rules and guidelines within which to catalog the patient to be treated, difficult to apply and not always applied. The increase in health needs and attention to the economic component has made it necessary to resort to an organizational-management system to try to balance costs with the satisfaction of needs.

Comment: The Management Medicine presupposes an adequate organization of the system to give the necessary answers to the needs of patients; but at the same time, due to the availability of resources, it causes a series of distortions such as the provision of examinations (quantity rather than quality) and not the solution of problems, inadequacy of the organization with ineffective coordination between physicians and services, reservations through a single reservation center which, given its organizational base, often becomes ineffective and causes long and discouraging waiting lists (cerebral-uneffective process of reservation) with consequent overload of First Aid. Health protection activities can become uneffective if not coordinated with productive, environmental and social ones. All of this contributes to generating waste by diverting resources from care, quality of services, efficiency and innovation. The amount of waste in the balance of Italian Minister of Health for the year 2017 was of 21,59 billion of Euros and represent around 20\% of total expenses [38]. Numbers are used and necessary in Medicine, but Medicine of numbers is a distortion of medical practice. Numbers, statistics and guidelines are valid supports in medical practice as long as taken into account in the context of anamnestic and clinical evaluation of the patient. Health professionals, patients, policymakers, and the public aspire to making healthcare decisions on the basis of the best available research evidence. However, experience shows that this frequently is not achieved, due to the overwhelming amount of research literature, sometimes contradictory, and presentations that are difficult for non-researchers to be understood, the best estimates of the expected benefits, the harms of a therapy or intervention, level of quality of the evidence, patient values, preferences, and for policy makers in particular, resource use, feasibility, and equity; in addition implementations, benefits and impact on health outcomes are poorly detected (between $4,2 \%$ and $12 \%$; between $53 \%$ and $56 \%$ in case of acute, preventive and chronic care) [3941]. Modern Western Medicine is based on a narrow "scientific" model, and arrogantly ignores and rejects therapies and entire medical systems that don't fit this model [42].

\section{Patient}

Hippocratic definition: The patient represents the fragile person, one of the components of the sick triad that includes illness and physician (....the physician is the minister of the art, the sick opposes to the evil together with the physician - Hippocrates), the person to know as a whole in order to understand the disease and be able to cure it. 
Modern Medicine: the patient is defined as a person who becomes aware of the disease, perceiving the organic, functional, psychological and social imbalance.

Critical issues: Given the panorama of health assistance and care for the sick and protection of the right of health, very often the patient is called customer or user. In fact, physicians treat the disease and not the person with that disease.

Comment: the continuity of care is not always guaranteed, understood as an integrated system of accompanying the patient in his different phases of need [43]; this generates consumption of resources (also for inappropriate examinations) to satisfy needs that could be satisfied better and with less resources, and absence of continuity of assistance. The physician should understand that in treating a sick man and not a disease without a humanistic approach to the profession, the application of modern medical science will remain sub-optimal, even damaging....Instead of treating the underlying causes or imbalances, Physicians often merely manage symptoms. Symptoms are seen as something to be suppressed rather than a pointer to some underlying imbalance. Physicians see the human body as a machine with separate parts that can be treated independently rather than as an integrated whole. In addition, the mind and body are also seen as separate independent entities and emotions are often ignored. We treat the disease, not the patient. There is a reliance on numbers and tests rather than how the patient is feeling and what is found on examination [42]....one of the essential qualities of the clinicians is interest in humanity, because the secret of the patient care is in caring for the patient [44].

To attend those who suffer, a physician must possess not only the scientific knowledge and technical abilities, but also an understanding of human nature. The patient is not just a group of symptoms, damaged organs and altered emotions. The patient is a human being, at the same time worried and hopeful, who is searching for relief, help and trust. The importance of an intimate relationship between patient and physician can never be overstated because in most cases an accurate diagnosis, as well as an effective treatment, relies directly on the quality of this relationship [44].

\section{Diagnosis}

Hippocratic definition: Diagnosis is based, according to Hippocrates, on the anamnesis, etiology, clinical and semeiotics.

Modern Medicine: the diagnosis is defined, in a manner not very different from the past, as the process by which the physician defines the disease by relating the disorders reported by the patient (anamnesis), the objective data he detected with the examination (objective examination) and the results of instrumental examinations when necessary.

Critical issues: Very often medical activity is disengaged from the clinical context (requests for instrumental tests on the patients' proposal or on the basis of single symptoms in the absence of necessary and complete clinical anamnestic assessment), is practiced with insecurity and fear of being cited in court. We often resort to technology with a demand for examinations for various reasons, however, outside the clinical context and the diagnostic process (too much reliance on technology) with a consequent increase in the inappropriateness of examinations and temporal data.

Comment: The request for exams coming from the clinical context, the clinical interactions, the way to communicate with the patient, the modality to perform a diagnosis must be the essential basis for the diagnostic process and the correct interaction with the patient (There is a reliance on numbers and tests rather than how the patient is feeling and what is found on examination...) [42]. Technology and instrumental examination have given a great impulse to the possibility to increase and improve diagnosis, but they should be used in an appropriate manner; the major danger that could come from them is to replace themselves to the methodology and observation of the patient, leading the physician to the reconstruction of mosaic fragments, represented by the results of research, often instrumental, performed on the different apparatuses and organs, often by more specialists.

\section{Appropriateness}

Hippocratic definition: Do no harm (primum non nocere), do what is necessary (Hippocrates).

Modern Medicine: appropriateness is defined as doing the right things to those who need them when needed. Health procedure which is more likely to produce a benefit than a damage and which can be carried out at a reasonable cost and risk. The ethical value of non - maleficence in Medicine [45,46].

Critical issues: Unfortunately, the number of examinations and therapies that are not always appropriate and useful is constantly increasing; we put more attention to the economic appropriateness than to the clinical one and often we try to solve the problems of patients with instrumental tests, sometimes repeated, often clinically inappropriate and unusual, when they could be solved with greater attention to the patient as a person, with his history and symptoms.

Comment: the number of inappropriate tests and admissions and of repeated unnecessary instrumental exams and admissions is increasing due frequently to different reasons. This leads to overuse of services and examinations (laboratory tests, instrumental investigations, specialist consultations, hospitalizations, etc.) which has an economic impact on public health of about $€$ 9-10 billion/year (Pilot study, National Agency for Health Services, Italy, 2014).Overuse and unnecessary care account for anywhere from one-third to one-half of all health costs, which equal hundreds of billions of dollars, in addition to the half-a-trillion per year experts attribute to lost productivity. Early elective deliveries are unnecessary, according to the American College of Obstetricians and Gynecologists recommendations, nonetheless, a dramatic escalation in the rates of these deliveries from the 1990s to the first decade of the new century has been recorded. 


\section{Humanization}

Hippocratic definition: Intended as attention to the needs of the patient, love for the patient and personal care.

Modern Medicine: it is inserted today in an organizational, structural and relational context in which the patient as a person with his feelings, his knowledge and his beliefs about his state of health is at the center of the cure and the different competencies revolve around him in order to satisfy all his health needs (Italian Health Pact 2014- 2016 committing Regions and Autonomous Provinces to implement structural, organizational and related interventions).

Critical issues: the conditions are not always favorable; there is not always an adequate interest for the patient as a person due to the difficulties of identifying the taking into care of the patient himself and the responsibility of the therapeutic diagnostic processes. Waiting times, environments that are not always adequate, reception, respect for privacy, assistance and, sometimes, inaccurate and fragmented information are among the main components of the occurrence of discomfort and of uneasy situations.

Comment: It is important to define a system that takes into account the needs of all the actors involved (patient and health operators) and create the human conditions of action, moving and living; these represent the underpinning of a qualified and human assistance and care that every health worker in professional practice should feel and be ready to do [47]. Humanization and its application to the patient care should be part of physician's training, included the respectful attentiveness and a genuine commitment to a patient's welfare; it should be instilled on the ward, office and clinics under the watchful mentorship of seasoned physicians [48]. With Modern Medicine and the evolutive changes we assist to a prevalence of the biological being on the personal being, of the personal being on the human being, of the scientific knowledge on "humanistic" knowledge; this tendency should be inverted with an assumption of an ethics of responsibility and replaced by the promotion of the prevalence of the human being on the personal being and of the personal being on the biological being [49]. Hippocratic physicians were deeply committed to creating an environment of concern, trust, and hope in their relationships with patients and families and to be mindful of the ethical lessons they give in the relationships. The Hippocratic essays remind us that medicine is the most human of the scientifically based disciplines because, at its best, its practice embodies our most civilizing values. [50,51].

\section{Therapy}

Hippocratic definition: therapy is defined by the triad of diet, medication and exercise.

Modern Medicine: it is represented in fact by drugs, surgery and lifestyle to which rehabilitation must be added (even if it is not always applied to the patient).
Critical issues: while much attention is given to drug therapy, interventional and surgical, little information is given on the use and management of drugs (this contributes to reduced adherence to therapy) and poor recommendations are given on lifestyle, physical activity, nutrition, because many physicians do not take into account the importance of it [42]; little or no attention to the psycho-behavioral aspects of the patient who are behind an inadequate and often deleterious lifestyle.

Comment: More than 80 percent of all medical treatments used have been untested by rigorous peer reviewed study, yet the Medical establishment insists that alternative health treatments must undergo these before they can be used. The system of evaluation needs to be changed [42]. The definition of the patient's psychological profile is the first step for the therapeutic alliance [52]... the physician must study the habits, lifestyle and age of each patient; the speeches, the silences, the thoughts, the sleep, the insomnia, the dreams - how and when - the involuntary gestures, the torn hair, the scratches, the crying ...... because the biggest mistake that can be committed today is to separate the psyche from the soma ... [34].

\section{Communication}

Hippocratic definition: communication with the patient is fundamental as well as a precise duty of the physician. It must be simple and understandable.....it seems to me that we should, speaking of this art, say things that are understandable to the profane.... bear in mind your manner of sitting, reserve, decisive utterance, brevity of speech, composure [53]. The dignity of a physician requires that he should look healthy, and as plump as nature intended him to be; for the common crowd consider those who are not of this excellent bodily condition to be unable to take care of others. Then he must be clean in person, well dressed, and anointed with sweet-smelling unguents. .... [54].... I think the best physician is the one who has the providence to tell the patients, according to his knowledge, the present situation, what has happened before, and what is going to happen in the future [55].

Modern Medicine: Today communication represents the clinical interview with which the patient tells the story of the disease, its subjective experience, its emotions and its psychic defenses; it also represents the information that the physician gives to the patient, health education and counseling.

Critical issues. In many cases, physicians are not prepared for effective communication (with patients, relatives, other health professionals, with work tools such as medical records, with the general public) and this is one of the causes of complaints and disputes. Physicians often maintain a style of high control, which involves many physician-initiated questions, interruptions, and neglect of patients' "life world". The interviews are often approximate, sometimes incomprehensible or inexistent, inadequate and insufficient information; communication is often aimed at compliance with legal obligations. Informed consent is not always applied correctly. From the Health Test survey October 
2010 - No. 88, performed in some European Countries, the most majority of patients reported poor or not existent communication, with a physician increasingly interested in the use of technology and drug prescriptions. Physicians tend to underestimate patients' desire for information and to misperceive the process of information that is being given. There is a suboptimal (in many cases absent) communication and information exchange between specialist and general practitioner.

Comment: in the absence of narration, the patient's world remains unknown and the possibility of understanding the readiness for change and treatment remains compromised. The transmission of information is related to characteristics of patients (sex, education, social class, and prognosis), physicians (social-class background, income, and perception of patients' desire for information), and the clinical situation (number of patients seen). Information transmittal is usually associated with physicians' income, social class background, political ideology, and perceptions of patients' information needs, situational characteristics such as the length of acquaintance, numbers of patients seen per day, and the types of patients in the physicians' practices. One doesn't forget that physicians' nonverbal communication abilities as well as his presentation are associated with outcomes of medical care such as satisfaction and compliance [56]; in addition, communication in medical care is highly correlated with better patient adherence, and training physicians to communicate better enhances their patients' adherence [57]. Prescribing a battery of tests, and coming to a potential diagnosis, means little if that information is not properly communicated. Patients and their relatives well understand the situations where physicians are operating, the difficulties and the fact that healing is not always guaranteed; they do not understand medicine and do not judge professional competence of physicians. They want and need to be informed and judge physicians on his behavior and how he has related with them. The major causes of legal disputes are due to a bed relationship and scarce or no information. Communication and information exchanges are most important between specialist and general practitioner and among specialists for the correct and fruitful management of the patient and of his pathway; at the same time, it is important to identify who coordinates physicians' relationship, who puts together information and who has the responsibility to take decisions.

\section{Physician-patient relationship}

Hippocratic definition: the physician-patient relationship was paternalistic, asymmetric between the power of the physician and the submission of the patient, in any case seeking an alliance to overcome the disease.

Modern Medicine: it is defined as the relationship whose contractors, autonomous, equal and with the same negotiating power, freely sign a pact. Relevance is given to the duty of the physician to inform the patient and obtain his consent, and the patient's right to decide which medical treatment to undergo or not (informed consent).
Critical issues: Among the factors that influence the relationship with the patient we recognize the cure of the disease by the physician, the poor relationship of trust, the inversion of roles that can often occur (when the patient asks the physician what tests he wants to undergo or drugs to take), a lack of empathy, bureaucratic pressure and procedural aspects, communication difficulties, technology (performance) in place of the clinic. All these contribute to result in a lack of knowledge of the patient's experience and to determine a lack of counseling and defects in taking care of patients.

Comment: On considering a relationship that is based on mutual participation of two individuals, the term "relationship" refers to an abstraction encompassing the activities of two interacting systems or persons. The apparent, intrinsic quality of this unique physician-patient relationship allows two people, previously unknown to each other, to feel at ease with variable degree of intimacy on fully, physically, psychologically, sexually, and so forth [58]. This relationship, in time, may develop to allow the patient to convey highly personal and private matters in a safe and constructive environment. It must be kept in mind that the physician-patient relationship remains asymmetric in that the patient, the most vulnerable part, is dependent on the competence and power of the physician(Italian Consulta su Bioetica).The role of the patients has been changed: most of them trust their physicians' judgment but want a second opinion for major treatments and decisions, and they pursue those on their own, want to learn more about their condition from sources that are evidence-based and independent, believe they should have complete access to their own medical record without cost or hassle, think their physicians should leverage online technologies to allow online scheduling, tele-visits, secure messaging and more, want their physicians to embrace alternative therapies and lifestyle interventions in their recommendations, want their physician to tell them what a procedure or encounter will cost ahead of time to avoid surprises; all want to know their physician's track recordoutcomes, patient ratings, and more, all want their clinicians to disclose their conflicts of interest, i.e. business relationships influence their referrals, all want their physicians to treat them with respect and listen to them better, all think their practices should provide better service that is convenient, accessible and person-centered. Little wonder if half of all patients say they are open to making a change and most think physicians are focused on their own needs rather than theirs [59]. The impact of a national healthcare system results in rushed clinic visits, inadequate clinical evaluations and little opportunity to establish a rapport with patients; this leaves patients and physicians unsatisfied with the quality of the encounter [60]. Nowadays, complete, correct and comprehensible communication is a primary exigency for the physician, for the patient/person and for all the organizational levels of the health system. Every physician and, more in general, every health operator, must therefore learn to communicate effectively in the course of his/her medical training, and must continually refine this capacity during his/her professional career. 
The level of courtesy of both administrative and clinical personnel during access and hospital/office stay provide the feeling that patients are important and respected, as do reasonable waiting times and attention to personal comfort; the availability of nurses and doctors contributes to give a sense of security. In this, patient-centered culture organization has an important role [61]. The physician-patient relationship is central and important in medical practice, especially, in critical situation where patients are more vulnerable as they experience a heightened reliance on the physician's competence, skills, and good will [61]. Strong physician - patient relationships are associated with higher ratings for physicians and better outcomes for patients.(... if we lose the understanding of the common man the reality will be lost ... it would not be possible to know Medicine for those who do not know what man is, but it is precisely this that should understand those who must properly take care of man) [33].

\section{Instruments}

Hippocratic definition: The instrumentation is important for the physician to help him to correct abnormalities, such as phlebotomy for humors, trephination and surgical procedures. But the health documentation (medical record) is also instruments, that is the collection, registration and cataloging of data, organized according to a rational scheme and compared and verified with experience.

Modern Medicine: Medical tools and technology must increase therapeutic diagnostic skills without causing harm to the patient. The health documentation is a legal requirement that collects clinical reports and instrumental diagnostics and all that will be or be done to the patient.

Critical issues: Technology sometimes replaces the methodology, the clinical classification and the observation of the patient. It produces sometimes useless tests and the request for exams is often made out of the clinical context. The clinical record is not always written in a complete and correct way.

Comment: The interview with the patient, the correct interaction with him and his clinical classification that allow the diagnostic orientation, must be the essential basis for the diagnostic process. The technology is inserted between physician and patient and represents the sixth sense of the physician giving him new opportunities in diagnostic comprehension and therapeutical interventions. The great and awesome technological development has improved diagnostic and therapeutical possibilities and for these reasons, technology must be used in an appropriate and useful way. The correct and complete compilation of clinical record not only is a precise duty by law but also represents the safeguard document for both the physician and the patient.

\section{Discussion}

We have tried to see with Hippocrates' eyes what his Revolution has left in the Modern Medicine after 24 centuries of social, economic, political, cultural, health, scientific and technological changes. All the basic concepts such as Medicine, Disease, Physician, Patient, Diagnosis, Therapy, Prognosis, Education, Appropriateness, Humanization, Communication have remained intact with slight changes of form in their evolution and some distortions in their application, without the substantial definition being affected; as well as the primary objective of medicine has remained the same (to get rid the patients from suffering and containing the violence of the disease). All the distortions described above are attributable to the Health System and Organization and within it they appear to be more compromised in their daily application.

The incredible increase in health needs and the introduction of the protection of the right to health together with the guarantee of assistance has made necessary the creation of Medicine (Health) as a System with an articulated organization and linked to the economic system in relation with fundamental principles as quality, accessibility, equity, uniformity, effectiveness, efficiency, solidarity and security of health care and services in general for all citizens.

The protection of citizens' right to Health and guarantee Care in all cases when they are needed is an absolute and nondisputable principle that belongs to the developed countries but it should belong to all countries; however, when its application is linked to the economic resources, then, words such as equity, accessibility to services and care, quality, etc. are emptied of their absolute meaning and can become optional in many cases. When Health is linked to the economic resources it is necessary that the country respects another principle, that is honesty: honesty of the State to be the first to fulfill its payments, honesty of the citizens to be always punctual to pay the amount due in taxes and then, honesty of the operators to carry out their work and their services correctly and in a non-corruptive manner. Furthermore, assistance and access to care require immediate, not derogable intervention that can never be denied regardless of the availability of economic resources.

The protection of Health, on the other hand, is something regarding the prevention of the diseases and lifestyle, included in the family, social, work, economic and environmental context, whose costs should be attributed to all the structures, institutional associations and ministries involved so to direct their policy to projects to achieve in absolute safety and wellbeing and citizens' behaviors towards more suitable lifestyles and more targeted and effective prevention programs. This gives responsibility to all stakeholders in planning projects and control regular and healthy activities without pollution or risks for health and security for workers and environment. In the absence of separation of Health protection from guarantee of assistance, both from a management and economic point of view, the system runs the risk of imploding because one absorbs resources from the other with consequent increase in costs, reduction of resources for priority activities, inappropriateness at all levels and significant waste, with the final result that only what will be sustainable based on the availability of economic resources will be guaranteed. We believe that this 
was not exactly what Hippocrates dreamed of. In this context, the operativity of the Physician-Patient alliance to combat the disease, suffers negative interferences both as regards to the physician in the interpretation and practicing his profession, and as regards to the patient in the satisfaction of his health needs.

Improved care and reduced mortality have led to an increase in survivors and chronic illnesses whose management requires a revision of the care system that has become inadequate to make it more equitable and sustainable while respecting the basic principles mentioned above. Among the various sectors to be reformed there would be the reinforcement of territorial services and an approach based on the health of initiative with the aim of contrasting with greater incisiveness and effectiveness the inadequacies and inequalities in meeting health needs and combating suffering and mortality linked to chronic diseases. (Preventing chronic diseases: a vital investment, 2005 WHO Report). With current knowledge, chronic diseases can be prevented and controlled; to do that, integrated and broadspectrum interventions are needed [62]. Multidisciplinarity of interventions, therapeutic diagnostic pathways, taking care of the patient's path, continuity of care, understood as an integrated system of accompanying the patient in his different phases of necessities [43] and a follow-up plan are fundamental activities within a modern healthcare organization that seeks to meet the health needs of patients in accordance with the Hippocratic principles (more time to know the patient, feasibility of the diagnostic process, appropriateness of examinations and hospital admissions, adequate communication, training and respect of roles and competencies, more attention to their problems and their psychological profile) [63]. Even the physician recovers credibility and has the opportunity to re-appropriate his profession by giving it back the prestige and, above all, the fundamental role in the alliance with the patient and in the management and assumption of responsibility for the patient, his family and society.

The physician will have to recover his mission, patiently and effortfully, to safeguard the Health of people according to the World Medical Association with the Declaration of Helsinki of 1964, which refers to the Hippocratic principle according to which the doctor takes care of the patient according to his needs and in complete freedom of care. No patient can be treated according with his necessity if the doctor is not free to practice because he must submit his activity to rules and impositions that have the sole purpose of safeguarding economic resources. A bureaucratized physician loses sight of the patient and his profession. But it is physician's duty to defend his profession and his role in Medicine... before they are supplanted by any profane idiot that pretends to be a physician: the Jew, the friar, the hedgehog, the barber, the old woman; as the alchemist or the soap maker, or the custodian of the baths, or the false oculist, do as physicians. So, while many people are looking for profit, art loses its value.... (Flos Salernitanum) [64]; the risk is to dismember medical practice in many other competences with improper attribution of decisional responsibility that would lead to irreparable damages for the medical profession, physicians and patients.

One last aspect to consider is that regarding to the conditions and difficulty in which the physician often works and the not fully exercised professional role, fundamental for the management of the patient's path; these situations will surely lead to an increase in the legal disputes with the patients within the medical field. In fact, the physician will be more forced to operate within guidelines or schemes that, bound to numbers and statistical evidence, are far from the real world consisting of the clinical case and patient singularity, to follow bureaucratic practices often useless, to satisfy mandatory demands with deleterious inversion of roles; for these and many other reasons he will find himself working with insecurity and consequently making actions oriented more to guarantee his work than to the benefit of solving the patient's problem. We can affirm, aware of going against the trend, that what has been defined as Defensive Medicine does not exist but it is only an expression of the difficulties in which the physician works, which depend on insecurity, inadequate experience, scarce ability to take responsibility, inadequate management capability of clinical situation of the patient, inadequate work organization, structural deficiencies and external pressures of various order and degree.

\section{Conclusion}

Hippocrates has been very famous either in life or after death until today. So famous and good physician that still in life he was identified as a God. His profession as a physician was a noble profession for the characteristics of the profession itself. The same Hippocratic revolution of Medicine has been so enlightening in the principles that even today they constitute the underpinning of Modern Medicine. Just in view of this, we believe that, despite the various distortions, Hippocrates' Ars Medica can coexist with Science and Management Medicine, including Technological supports. In our opinion, the balancing of the four components allows to have to day and in the future a more human, effective and efficient Medicine. This will be possible if the Organization will put the physician in the conditions to operate at the best of his abilities and prerogatives, the Patient will be appropriately informed about his state of illness and use of health structures and educated to best manage his clinical diagnostic therapeutic and rehabilitative pathway, the Physician will re-appropriate his role and responsibility, not delegable to others, in the relationship with the patient and in the management of the patient himself with his illness based on the close alliance between these and the System.

According to the Hippocrates' teachings, it will be up to the physician to become an active part in defending Medicine in its attributions and principles, defending the profession and his role in the alliance with the patient, taking responsibility established by law of the patient pathway, demanding respect for his prerogatives, contributing to the realization of the organizational work context and laying. Persons and physicians 
when come together in medical relationship have expectations, hopes, needs that should be understood and respected; for this human relationship, Medicine is a great scientific based discipline, a difficult art, developing science, complicated to manage, that needs high morality and, above all, love for itself and for humanity; if there is love for man, there will also be love for science [65].

Another emerging and growing problem is the use by the patients of social media for health-related issues and the spread of fake news. The former may have beneficial and potentially harmful effects, which can affect the healthcare professional and patient relationship [66]. Physician should change their approach to the patient and, because he is more informed, should experience a new relationship, more empathic, satisfying, useful and clearer. The fake news represents today a serious problem that can negatively affect not only the physician patient relationship but also the whole system of healthcare. It is important to affirm the principle that Science is not under discussion by anybody but scientists, science cannot be disputable by anybody if not competent scientists. Science, especially medical science, cannot be used freely by politicians, intellectuals, media or any other else, without the binding skilled support of scientists. Physicians should be aware and learn to measure themselves with these phenomena; and in their practice protect Medical Science and profession from the spread of fake news.

Finally, in addition to ethical aspect, there is another great problem facing Medicine to day and it is the uninspired voice of physicians who have lost their faith and interest in the medical work they do, interpret the medical profession pursuing more economic success than professional one and do not show deep appealing to medicine, with unavoidable consequence that their voice and behavior will deter the intelligent and optimistic youth from believing in and pursuing this great work. This trend should be changed recovering values and principles of this noble profession. It is time to move towards the foundations of a new alliance with patients and with the Organization, to be reestablished on the base of ethical principles to practice Medicine as a conjunction of Art, Science and Management; only in this way do we believe that it is possible to negotiate and collaborate with the System but, above all, only so, that having submitted to the Hippocratic Oath will not have been in vain.

\section{References}

1. Gino Gullace (1973): Da Oggi n. 36, Rizzoli Ed.

2. Vegetti M (2000) (a cura di), Opere di Ippocrate, Torino, Utet.

3. Hippocrates of Cos (1923) The Oath Loeb Classical Library. 147: 298299.

4. FNOMCeO (1998) La storia del codice deontologico. e 2012.

5. Callaway E (2014) Nature.

6. Vernot B, Akey JM (2014) Resurrecting surviving Neandertal lineages from modern human genomes. Science 343(6174): 1017-1021.

7. Villa P, Roebroeks W (2014) Neandertal demise: an archaeological analysis of the modern human superiority complex. Plos One 9(4): e96424.
8. Prioreschi P (1996) History of Medicine Volume 1: Primitive and Ancient Medicine. Edwin Mellen Press p. 257f. ISBN 978-0-77349661-3.

9. Brelet-Rueff C (1991) Le arti mediche dall'antichità ad oggi. Sperling and Kupfer Ed, Paris, France.

10. Uhlig H, Sumeri I (1997) Enmerkar e il signore di Aratta, IV millennio a.C, Garzanti Ed, Milano, Italy p. 83.

11. Kramer SN (1981) History bigins at Sumer. University Pennssylvania press, United States.

12. Saporetti C (1998) Antiche leggi, Rusconi Editore, Milano, Italy.

13. Contenau G (1996) La civiltà degli Assiri e dei Babilonesi. Libriitalia Ed., AC Grafiche, Cerbara di Città di Castello.

14. Oates J (1984) Babilonia, ascesa e decadenza di un impero, Newton e Compton Ed, Roma.

15. Edwin Smith papyrus (Egyptian medical book) (2016) Encyclopædia Britannica (Online ed.).

16. Arab SM (2011) Medicine in Ancient Egypt - Part 1". Arab World Books.

17. Arab SM (2011) Medicine in Ancient Egypt - Part 3". Arab World Books.

18. Nunn JF (1996) Ancient Egyptian Medicine. Oklahoma: University of Oklahoma Press, Norman, OK, USA.

19. Jacq C (1997) Il mondo magico dell'antico Egitto. Oscar Mondadori, Milano, Italy.

20. Sterpellone L (1990) Stratigrafia di un passato. Storie parallele della Medicina, Ed Punto e Linea, Milano, Italy.

21. Leca Ange-Pierre (1986) La medicina egizia. Ciba-Geigy Ed.

22. Pazzini A (1973) Storia dell'arte sanitaria, dalle origini ad oggi. Edizioni Minerva Medica, Roma, Vol. I.

23. Erodoto: Storie (libro III, par. 133).

24. Geoffrey E Lloyd (1993) Metodi e problemi della scienza greca, traduzione italiana, Laterza, Bari-Roma.

25. Maddalena I (1986) I Presocratici Testimonianze e frammenti in G. Giannantoni (a cura di), Bari-Roma, Laterza, vol. I.

26. Focà A Dalla memoria alla speranza: Alcmeone e la tradizione medico filosofica calabrese.

27. Focà A La prima scuola di medicina a Crotone, la rivoluzione del pensiero scientifico e l'espansione nel mediterraneo.

28. Bruni Aretino P (1837) Cenno storico intorno la scuola medica di Crotone, Archivio Scienze Medico Fisiche Toscane, Anno I, Fasc III, Tipografia della Speranza, Firenze, Italy.

29. Carugo B (2006) Breve storia della medicina, della diagnostica e delle arti sanitarie. Seconda Edizione, p. 1-127.

30. Ippocrate (1983) Testi di medicina greca, Biblioteca Universale Rizzoli, Milano, Italy.

31. Corpus Hippocraticum, Malattie delle donne, capitolo LXII, ed. Littré.

32. Ippocrate ed il Corpus Hippocraticum. Da Émile Littré: Hippocrate. Oeuvres Completes (Traduction Nouvelle, avec le texte grec en regard). Traduzione di De Luca C.

33. Ippocrate - Sull'arte, in Opere, p. 461.

34. Ippocrate - Epidemie VI, 3, 12.

35. Aristotele (1973) Opere, Roma-Bari, Italy.

36. Cartabellotta A (2011) Rapporto GIMBE.

37. The European definition of General practice/Family medicine. WONCA (World Organization of National Colleges, Academies and Academic 
Associations of General Practitioners/Family Physicians) Europe 2011 edition.

38. Cartabellotta A (2018) $3^{\circ}$ Rapporto GIMBE sulla sostenibilità del Servizio Sanitario.

39. McGlynn EA, Asch SM, Adams J, Keesey J, Hicks J, et al. (2003) The quality of health care delivered to adults in the United States. N Engl J Med 348: 2635-2645.

40. Grimshaw JM, Eccles MP, Lavis JN Hill SJ, Squires JE (2012) Knowledge translation of research findings. Implement Sci 7: 50.

41. Kredo T, Bernhardsson S, Machingaidze S, Young T, Louw $\mathrm{Q}$ et al. (2016) Guide to clinical practice guidelines: the current state of play. Int J Qual Health Care 28(1): 122-128.

42. Lipman F (2010) CARE2 HEALTHY LIVING.

43. Freer SD (1999) Whither continuity of care? N Engl J Med 341(11): 850-852.

44. Hellĩn T (2002) The Physician-patient relationship: recent developments and changes. Haemophilia 8(3): 450-454.

45. Gillon R, Lloyd A, eds. (1994) Principles of health care ethics. John Wiley \& Sons, Chichester, UK.

46. Leake CD (1975) ed. Percival's medical ethics. Huntington, NY: Robert E Kreiger Publishing Company, USA.

47. Gullace G, Lucisano V, Granata A, Ferrante A, Damaschi V, et al. (2000) Umanizzazione e sistema qualità in una unità operativa di cardiologia riabilitativa. Giorn. Riabilitazione XVI(3): p.192.

48. Satel S (2010) Physician, Humanize Thyself, The Wall Street Journal.

49. Campione F (2015) The Humanization of Healthcare Treatments and Critical Choices, in Callus E, Quadri E (eds.), Clinical Psychology and Congenital Heart Disease: Lifelong Psychological Aspects and Interventions, Springer-Verlag Italia 21-31.

50. Reiser SJ (2003) What Modern Physicians Can Learn from Hippocrates. American Cancer Society 98(8): 1555-1558.

51. Reiser SJ (1994) The ethics of learning and teaching medicine. Acad Med 69(11): 872-876.

52. Gullace G, Khalaf H (2011) Preclinical Diagnosis and Risk Assessment of Atherosclerosis -At Birth? At Event? When is Best? Eur Cardiol 7(3): 164-166.
53. Hippocrates D (1923) In: Jones WHS, translator. Hippocrates. Volume II. Cambridge, MA: Harvard University Press, 1923: 297, 293, 295.

54. Hippocrates (1923) The physician. In: Jones WHS, translator. Hippocrates. Volume II. Cambridge, MA: Harvard University Press 311

55. Hippocrates (1978) 'Prognosis' in Hippocratic writings. In Lloyd GER ed. Penguin classics. London: Penguin Books 170-185.

56. Stewart MA (1995) Effective physician-patient communication and health outcomes: a review. CMAJ 152(9): 1423-1433.

57. Zolnierek KB, Dimatteo MR (2009) Physician communication and patient adherence to treatment: a meta-analysis. Med Care 47(8): 826834.

58. Smith JM (2001) Personal Privacy: Cultural Concerns. International Encyclopedia of the Social \& Behavioral Sciences 11250-11254.

59. Keckley P (2017) The Decline and Fall of the Doctor-Patient Relationship. The health care blog.

60. Park JE (2018) The Impact of a National Healthcare System on the Doctor-Patient Relationship in Neurology. J Clin Neurol 14(3): 430-431.

61. Dorr Goold S, Lipkin M Jr (1999) The Doctor-Patient Relationship Challenges, Opportunities, and Strategies. J Gen Intern Med 14(Suppl 1): S26-S33.

62. Maciocco G (2011) Dipartimento Sanità Pubblica, Firenze, Italy.

63. Gullace G (2016) Behavioral Cardiovascular Risk Factors: Changing Perspective to Approach the Problem. Journal Cardiol \& Cardiovasc Ther 2(1): 1-5.

64. Sinno A (2013) Regimen sanitatis flos medicinae scholae salerni. Ugo Mursia Ed.

65. Jones WHS (1923) Introduction to the oath. In: Jones WHS, translator. Hippocrates. Volume I. Cambridge, MA: Harvard University Press, United States 296.

66. Smailhodzic E, Hooijsma W, Boonstra A, Langley DJ (2016) Social media use in healthcare: A systematic review of effects on patients and on their relationship with healthcare professionals. BMC Health Services Research 16: 442.

Your next submission with Juniper Publishers
will reach you the below assets
- Quality Editorial service
- Swift Peer Review
- Reprints availability
- E-prints Service
- Manuscript Podcast for convenient understanding
- Global attainment for your research
- Manuscript accessibility in different formats
( Pdf, E-pub, Full Text, Audio)
- Unceasing customer service
Track the below URL for one-step submission
https://juniperpublishers.com/online-submission.php

